\title{
INTEGRATING AND MANAGING BIM IN GIS, SOFTWARE REVIEW
}

\author{
El Meouche R. ${ }^{1, a}$, Rezoug M. ${ }^{1}$, HIJAZI Ihab ${ }^{2}$. \\ ${ }^{1}$ Université Paris-Est, Institut de Recherche en Constructibilité, ESTP, F-94230, Cachan, France \\ ${ }^{2}$ An-Najah National University, Nablus, Palestine \\ arelmeouche@adm.estp.fr,
}

KEY WORDS: BIM, 3D, GIS, Data Interoperability, spatial analysis, IFC.

\begin{abstract}
:
Since the advent of Computer-Aided Design (CAD) and Geographical Information System (GIS) tools, project participants have been increasingly leveraging these tools throughout the different phases of a civil infrastructure project. In recent years the number of GIS software that provides tools to enable the integration of Building information in geo context has risen sharply. More and more GIS software are added tools for this purposes and other software projects are regularly extending these tools. However, each software has its different strength and weakness and its purpose of use.
\end{abstract}

This paper provides a thorough review to investigate the software capabilities and clarify its purpose. For this study, Autodesk Revit 2012 i.e. BIM editor software was used to create BIMs. In the first step, three building models were created, the resulted models were converted to BIM format and then the software was used to integrate it. For the evaluation of the software, general characteristics was studied such as the user interface, what formats are supported (import/export), and the way building information are imported.

\section{INTRODUCTION}

Data conversion between these CAD/BIM and GIS systems is resulting in a enormous mismatch that are require a manual work to be undertaken, due to limitations associated with exchange of data and knowledge. In 3D, spanning a bridge between CAD and GIS is even more challenging (Oosterom et al 2006, Isikdag and Zlatanova 2009, Emgard and Zlatanova 2008, teghtmeijer et al 2009, Wu, and Hsieh, 2007). This is due to the following facts: existing CAD and GIS platforms have been developed independently with different purposes resulting in significant differences in terms of data formats they support, terminology they used, semantics of concepts they represent, reasoning techniques on which they are based, different scale representations, and transformation of the local (CAD) coordinates into reference system for both the horizontal and vertical coordinates, geometry modelling in both systems, CAD software provides all kinds of primitives to create geometric (and their visual attributes), it represent objects with different representations such as CSG and Sweeping, however these primitives are not supported in GIS (e.g. parametric primitives) while geospatial models mainly use BRep as the main geometrical representation method; Furthermore, CAD models usually do not store topologic information which is in fact an important characteristic of geospatial models (i.e. geospatial models use topology to store geometric information in a more efficient manner)., For these reasons currently CAD and GIS platforms are not interoperable. Recently and as a result of the developed building standard such as Industry Foundation Classes (IFC), the Integration between Geospatial information and BIM/CAD could have been achieved at semantic level [6]. Efforts deals with bridging the gap between BIM/CAD and geospatial information models are providing harmonization of semantics that allowing the interoperability at the data level (IFC explorer, 2008, Paul and Borrmann 2008, IFG, 2006) and as web services (Lapierre and Cote, 2008). Current building models are capable to store semantic information and spatial relationships of building elements in an object oriented data structures. As a result different tools are being developed that enable the transformation of building models to be represented using 3D City data model standards (BIM server 2009, IFC explorer, 2008) and thus enable the visualization within 3D geospatial context using GIS software which provide stand alone or add on extension which is limited for visualization purposes, and by doing so, neglects spatial analysis, the very core of a GIS system.

This paper provide a review to a number of GIS software and investigate its capabilities to integrate CAD/BIM in GIS and perform spatial analysis, different software's have been revised including: AutoCAD Map, Google and ArcGIS. The work includes developing a proof of concept data migration and analysis for BIM using ArcGIS.

\section{ONGOING WORK AND OUTLOOK}

\subsection{Modelling of the buildings}

The software's evaluations are based on the integration of three BIM models using selected GIS software's. The models were created using Autodesk Revit 2012 software, Revit is specifically built for building information modeling (BIM) providing a complete architectural design and documentation solution, supporting all phases of design and all architectural drawings and schedules required for a building project, from massing and conceptual studies through the most detailed construction drawings and schedules (Revit, 2013).

\subsection{Tests of import}

Revit offers multitude of possibilities of export. On one hand CAD's diverse formats such as dwg, $\mathrm{dxf}$ and dgn. On the other hand we have the format IFC, the great promise created by the International Alliance for Interoperability with the purpose of facilitating the interoperability between different actors in Architectural, construction and engineering industry (AEC) (Mikael Laakso, 2012).

This phase of the research has been based on testing each of these formats with different GIS software's. The objective of these tests is to analyze the result of each one of these integrations, since the purpose of the project is to manage the 
integration of the model with their database in a GIS system without any problem.

\subsubsection{DWG to Google Earth}

Google Earth is a virtual globe, map and geographical information program it maps the Earth by the superimposition of images obtained from satellite imagery, aerial photography and GIS 3D globe. Many people use the applications to add their own data, Google Earth is able to show all kinds of images overlaid on the surface of the earth and is also a Web Map Service client (Google Earth, 2013). Google Earth supports managing three -dimensional Geospatial data including 3d models such as buildings through Keyhole Markup Language (KML).

The process of integrating a BIM model in Google Earth is not straightforward; first it is necessary to open the BIM model in format .dwg with the software Sketchup. After several operations we will be able to visualize it in Google Earth.

The results nevertheless have not been satisfactory. The integrated model is a block and it does not contain any information with regard to its elements.

\subsubsection{DWG to AutoCAD Map 3D}

Autocad Map 3D is software that provides access to GIS and mapping data to support planning, design, and data management. The software is capable of working with both technologies CAD and GIS (Autocad Map, 2013). It can import most CAD format. Moreover, it provides the possibility to integrate, edit and analyze geospatial information.

After the tests was finished, the result was been a change in the structure of the model. A BIM model is formed by elements, such as walls, doors or windows, nevertheless, after integrating it in Autocad Map 3D, the model has been transformed in a model formed by meshes of polylines, in the structure of CAD. After this change in the structure, it is impossible to export the model again with its associated attributes; therefore, AutoCAD Map 3D still do not provide a valuable solution.

\subsubsection{To ArcGIS}

ArcGIS is a comprehensive GIS platform that allows users to collect, organize, manage, analyze, communicate, and distribute geographic information (ArcGIS, 2013). ArcGIS is capable of reading $\mathrm{CAD}$ formats and integrate them in GIS as layers. Using ArcGIS interoperability extension we performed the following converges for $\mathrm{CAD}$ and BIM formats.

\section{DWG to ArcGIS 10}

ArcGIS is capable of reading DWG format and integrate it in GIS as layers. Using ArcGIS interoperability extension ArcGIS brings the DWG file into five generic layers: annotation, multipatch, point, polygon, and polyline each contain entitylinked attributes. It is possible to query this resulted layer in ArcGIS and derive some information from it. However, this still did not provide a full solution since DWG is just representing the geometry of building objects with no any further attributes.

\subsubsection{2}

\section{DGN to ArcGIS 10}

DGN conversion was expected to be similar to DWG, but the test shows that the ArcGIS was able to bring this file as a set of points corresponding to the vertexes of every drawing elements.

\subsubsection{3}

\section{IFC to ArcGIS}

To import the IFC format into ArcGIS it is necessary to have the new ArcGIS extension / ArcGIS Data Interoperability. Using this extension the building is converted into ArcGIS as a collection of layers each represent one IFC entity with its entire attribute, therefore there is a need for a full understanding of the IFC schema so the user can extract the required information. The next section describes a proof of concept for IFC migration and analysis in ArcGIS.

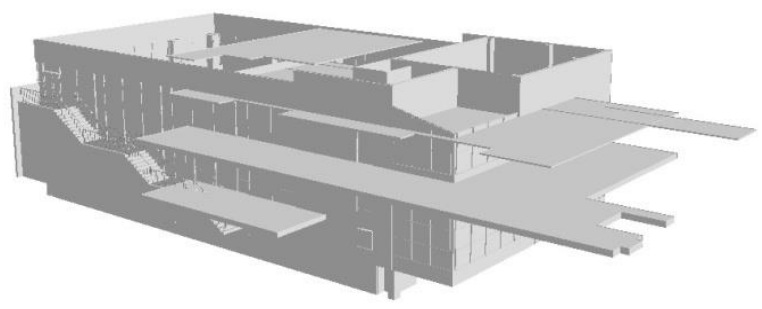

Figure 1 : Horizontal shift of the entire floor of the building

\section{PROOF OF CONCEPT DATA MIGRATION AND INTEGRATION IN ARCGIS}

ArcGIS Data Interoperability extension provide an easy integration of IFC files in ArcGIS, the result of the conversion is a list of layers each represent one entity associated with a table has columns represent the entity .

\subsubsection{Spatial adjustment}

ArcMap provide a tool for spatial adjustment of objects, using this tool the $3 \mathrm{~d}$ models was placed into its correct location. Coordinates are expressed in the French Lambert 93 projection system.

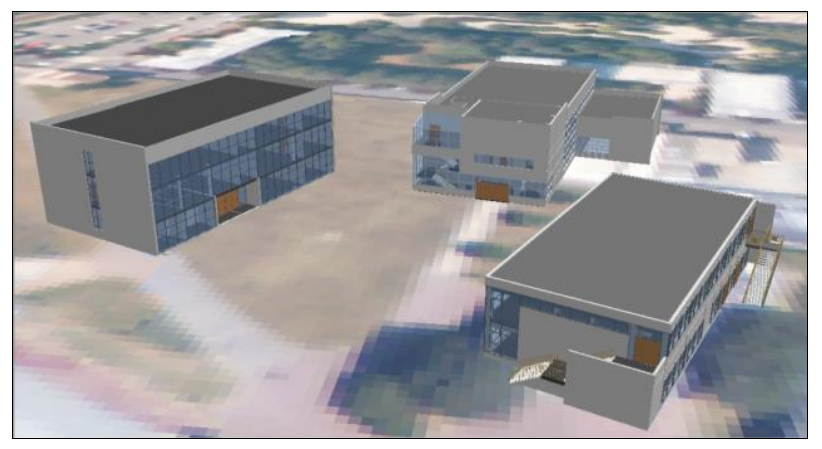

Figure 2 : BIM Models of 3 buildings

\subsubsection{Performing spatial quires}

After geo-referencing the 3D models were done. The models were visualized using Arc scene. Further we implement two queries, below is a description of these quires and its results

Query 1: Select all the doors which made from wood?

This query was performed using standard ArcGIS tools. It was done directly using select by attribute function on the door table, Fig 3 illustrate the query results. 


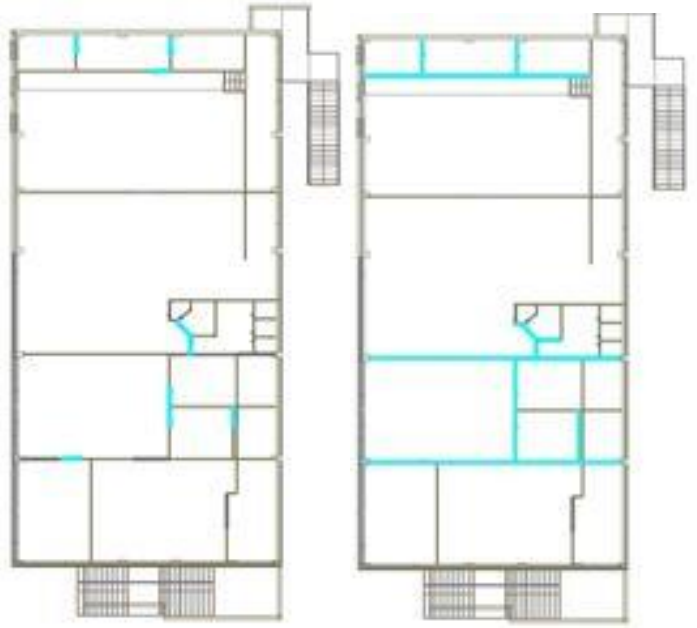

Figure 3 : Door selection based on attribute value-door material

Query 2: Calculate the total floor area of specific building in the university campus?

This query was not possible to be undertaken using the standard ArcGIS tools. Therefore a special tool is developed using ArcPay. The query was to calculate the floor area of the building "Vauban" from ESTP campus. The floor area of a building refers to the sum of floor area closed and covered under a ceiling with height greater than $1.80 \mathrm{~m}$. Therefore, we use Python to develop a script that is able to perform the required operation.
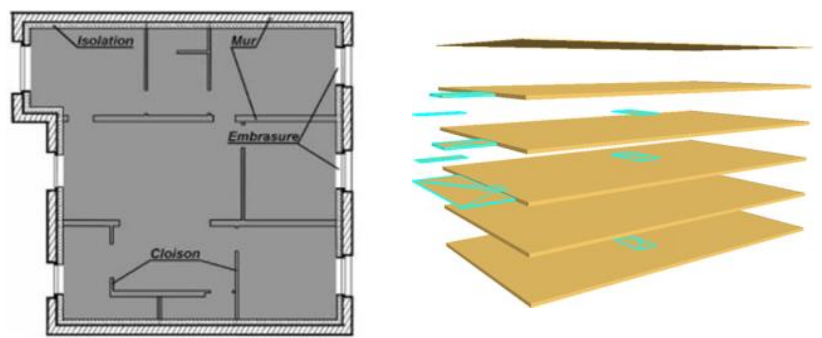

Figure 4 : using $3 \mathrm{~d}$ GIS functionalities to delete the non-floor surface areas/ unnecessary surfaces

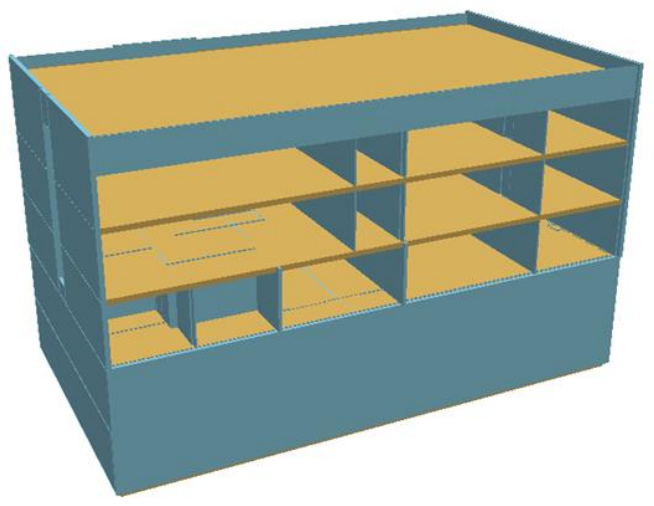

Figure $5:$ the resulted building after removing the non-floor surface areas

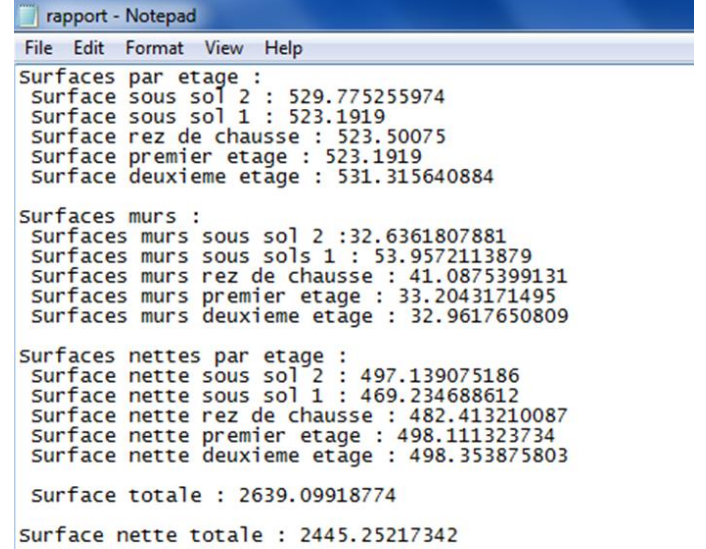

Figure 6 : the result of the query in textual format

\section{Expected result}

The work should provide initial understanding for the available software for integrating BIM information in Geo-context, also the type of information that can be integrated i.e. geometric and semantic. The investigation should also implement a number of trial conversions that will be carried out in future to investigate further the capabilities of ArcGIS to perform this integration.

Moreover, the work will investigate a new possible application for analyzing BIM in GIS. Also, this will include looking for developing scripts that automate the required analysis. The script prototype capabilities will allow us to develop a suitable 4. analysis.

\section{REFERENCES}

ArcGIS, 2013, ArcGIS 10.1 for Desktop, ESRI, http://www.esri.com/ products/. (Accessed January 2013)

Autocad Map, 2013, Autodesk® AutoCAD® Map 3D software, http://www.autodesk.com/products/autodesk-autocad-map3d/overview. (Accessed 10 April 2013),

BIM Server, 2009, Building information model server/converter to CityGML and KML, www.BIMserver.org, (accessed 28 Mai. 2010)

Google Earth, 2013, http://www.google.com/earth/index.html. (Accessed 5 April 2013).

Emgård, KL and S. Zlatanova, 2008, Design of an integrated 3D information model. In Coors, Rumor, Fendel \& Zlatanova (eds.), Urban and regional data management: UDMS annual 2007 (pp. 143-156), Taylor \& Francis Group, London, UK

IFG,2009, Industry Foundation Classes for GIS (IFG) (2009). http://www.iai.fzk.de/wwwextern/index.php?id=1040\&L=1 [last accessed 09-2010], Retrieved Mai, 20, 2009 from the World Wide Web: http://www.iai.no/ifg/Content/ifg_index.htm,

IFC Explorer, 2008, Tool for viewing and conversion of IFC models 
Isikdag, U, Zlatanova, S. 2009. Towards defining a framework for automatic generation of buildings in CityGML using building Information Models" in: 3D Geoinformation and Sciences J. Lee and S. Zlatanova (Eds), Springer Berlin

Isıkdag, U., Aouad, G., Underwood, J., Wu, S. 2007. Building Information Models: A review on storage and exchange mechanisms, In Daniel Rebolj (ed.): Proceedings of CIB W78 2007,Maribor, Slovenia Available online at: http://itc.scix.net/cgi-bin/works/Show?w78_ 2007_97 [last accessed 08-2010]

Lapierre, A. and P. Cote, 2008, Using Open Web Services for urban data management: a testbed resulting from an OGC initiative offering standard CAD/GIS/BIM services, in Coors,

M. Rumor, E. Fendel \& S. Zlatanova (eds.): Urban and Regional Data Management; UDMS Annual 2007, Taylor and Francis, London, pp. 381-393

Laakso M., 2012, The IFC Standard, A review of history, development and standardization, ITcon Vol. 17, pg. 134-161, http://www.itcon.org/2012/9.

Oosterom, P. van., Stotter, J., Janssen, E. 2006. Bridging the worlds of CAD and GIS, In: Zlatanova\&Prosperi (eds.) : Largescale 3D data integration -Challenges and Opportunities, Taylor\&Francis,, Boca Raton, pp.9-36

Paul, N., Borrmann,A 2008. Using geometrical and topological modelling approaches in building information modelling, In Alain Zarli and Raimar Schrer (eds) Proceedings of ECPPM 2008, CRC Press, pp.117-127

Revit, 2013, Autodesk Revit software for building design and construction,

http://www.autodesk.com/products/autodesk-revit-

family/overview, (accessed 5 April 2013),

Tegtmeier, W, S. Zlatanova, PJM van Oosterom, \& HRGK Hack, 2009, Information management in civil engineering infrastructural development: with focus on geological and geotechnical information. In TH Kolbe, H Zhang \& S Zlatanova (Eds.), Proceedings of the ISPRS workshop, vol. XXXVIII-34/C3 Commission Wheeler, D.A., 2005. Why Open Source Software/Free Software (OSS/FS)? Look at the Numbers!. http://www.dwheeler.com/oss fs why.html (accessed 28 July. 2010)

Wu, I., Hsieh, S. 2007, Transformation from IFC data model to GML data model: Methodology and tool development, Journal of the Chinese Institute of Engineers, 30(6), pp. 1085-1090. 